\title{
РОЛЬ ЦИФРОВОЙ ЭКОНОМИКИ В УСЛОВИЯХ ГЛОБАЛИЗАЦИИ
}

Шахгираев И.У., Макоев 3. М. ФГБОУ ВО «Чеченский государственный университет», г. Грозный

Статья посвящена исследованию теоретических аспектов иүирровой экономики в условиях формирования информационного общества и цифрровизаџии экономических отночений, глобализащионных экономических прочессов. Осуществлен анализ понятийно-категориального аппарата, который присутствует в исследованиях по проблематике цифррового развития экономики. Выделены особенности и основные принципь циифровой экономики.

Ключевые слова: цифровая экономика, государство, информационнокоммуникационные технологии, интернет, бизнес.

В условиях формирования информационного общества и процессов глобализации важную роль в развитии стран играет цифровая экономика, которая в свою очередь выступает основой развития общества на платформе информационно-коммуникативных технологий. Кроме того, развитие цифровой экономики является предпосылкой развития в нашей стране цифрового рынка.

В процессе развития информационного общества происходит формирование экономической системы информационного типа - цифровой экономики, характерной особенностью которой является активное использование информационно-коммуникативных технологий и сети Интернет.

Развитие цифровой экономики неразрывно связано с формированием информационного общества. В основе дефиниции «информационное общество» является положение о том, что количественные изменения в сфере информации привели к возникновению качественно нового типа социального устройства - информационного общества.

Общим признаком многих научных подходов к определению сущности цифровой экономики является попытка выделить широкое применении ИКТ в процессах общественного производства. Следует отметить, что практическая сторона этого вопроса значительно опережает теоретические наработки. Поэтому, для более широкого понимания дефиниции «цифровая экономика» рассмотрим трактовку экспертов ИТ-сферы. В частности, представители бизнеса в сфере ИКТ цифровую экономику рассматривают с таких позиций, как:

1) ... система экономических отношений, основанных на использовании цифровых ИКТ;

2) ... глобальная сеть экономических и социальных мероприятий, которые реализуются через такие платформы, как Интернет; 
3) ... модель взаимодействия участников экономических процессов, основанных на использовании современных электронных каналов связи и способов учета и хранения информации, с использованием электронного документооборота;

4) ... максимальная автоматизация бизнес-процессов внутри предприятия и взаимодействие с контрагентами и государственными органами путем использования современных информационных технологий;

5) ... использование информационных технологий в производстве, управлении, коммуникациях и т.д.;

6) ... это экономика, основой которой служат цифровые информационнокоммуникационные технологии;

7) ... когда все бизнес-процессы организованы в режиме онлайн, а эффективность обеспечивается информационно-коммуникационными процессами;

8) ... это экономика постиндустриального общества, которая характеризуется большим количеством как новых технологических средств, которые активно используются предприятиями, так и появлением цифровых каналов коммуникаций и переосмыслением подходов к использованию информации [3].

Из приведенных выше трактовок видим, что практики цифровую экономику рассматривают преимущественно как экономические процессы с активным использованием ИКТ и сети Интернет. Цифровая экономика - это модель взаимодействия всех участников экономических процессов информационного общества, которая построена на использовании ИКТ и электронных каналов связи с применением электронного документооборота.

Политико-экономическими целями цифровой экономики является:

- деловая среда, в которой компании могли бы в полной мере использовать возможности Интернета для конкуренции и внедрения инноваций в интересах пользователей;

- работники, предприниматели и государственные служащие, обладающие навыками, необходимыми для того, чтобы воспользоваться возможностями цифрового мира;

- государство, которое эффективно использует Интернет для расширения прав и возможностей граждан и предоставления услуг [2].

Все указанные принципы, без сомнения, являются основополагающими для развития цифровой экономики. Учитывая присутствие государственных институтов в процессе формирования экономических отношений субъектов цифровой экономики, должны применяться принципы, которые базируются на международных и национальных правовых нормах по защите прав человека, а также на общих принципах права, признанных международным обществом.

Для демократического развития государства важное значение приобретают принципы обеспечения доступа к публичной информации субъектов цифровой экономики. Всемирной организацией Open Societe Justice 
Initiative разработаны 10 международных принципов-стандартов по доступу к официальной информации:

a) максимальная открытость информации;

b) доступ к информации должен распространяться на все субъекты;

c) доступ к информации является правом каждого субъекта;

d) свобода доступа к информации;

е) процесс доступа к информации должен быть простым и быстрым;

f) необходимость на уровне закона определить точные условия отказа в доступе к информации;

g) гарантия права обжаловать решение об отказе в доступе к информации;

h) обязательство распорядителей публичной информации содействовать в предоставлении доступа к информации;

i) принцип превентивной публикации информации;

j) принцип гармонизации права на доступ к информации с другими законами [4].

Очевидно, что принципы цифровизации экономики - это основные идеи, принципы в соответствии с которыми должно развиваться цифровое электронное взаимодействие участников экономических отношений, и они должны быть заложены в основу разработки механизмов развития цифровой экономики. Развитие информационного общества, становление цифровой экономики обусловлено переходом к информационному взаимодействию, формированию электронной среды экономических отношений.

Процессы развития и преобразования экономики в цифровую происходит под влиянием многих факторов. Важную роль в содействии развитию цифровой экономики играют следующие основные факторы: цифровые финансы (внедрение цифровых технологий в банковский сектор, онлайн платежи, электронные государственные закупки и др.); социальные сети; цифровая идентификация; революция данных (в фокусе внимания находятся взаимосвязанные инновации - большие данные).

Организация экономического сотрудничества и развития (англ. Organisation for Economic Co-operation and Development) выделяет три основные составляющие цифровой экономики:

- поддерживающая инфраструктура (аппаратное и программное обеспечение, телекоммуникации, сети и др.);

- электронный бизнес или e-business (ведение хозяйственной деятельности и любых других бизнес-процессов через компьютерные сети);

- электронная коммерция или е-commerce (дистрибуция товаров через Интернет) [2].

Цифровая экономика продуцирует трансформационные процессы экономических отношений в цифровой формат. В этих условиях происходит развитие электронного формата взаимодействия участников экономических отношений. 
Цифровая экономика предполагает взаимодействие (обмен данными) между участниками процессов в режиме онлайн. Деятельность субъектов цифровой экономики раскроем через матрицу электронного пространства, где электронное взаимодействие субъектов цифровой экономики происходит между представителями бизнеса, потребителями и государственными органами (табл. 1).

Таблица 1 - Матрица электронного пространства

\begin{tabular}{|l|c|c|c|}
\hline \multicolumn{1}{|c|}{ Субъекты } & Государство & Бизнес & Потребитель \\
\hline Государство & G2G & G2B & G2C \\
\hline Бизнес & G2B & B2B & B2C \\
\hline Потребитель & G2C & C2B & C2C \\
\hline
\end{tabular}

Источник: составлено автором

Субъекты и направления электронного взаимодействия участников В2В цифровых экономических отношений приведены в таблице 2.

Таблица 2 - Электронное взаимодействие субъектов В2В цифровой экономики

\begin{tabular}{|c|c|}
\hline Субъекты & Направления электронного взаимодействия \\
\hline $\begin{array}{c}\text { бизнес }- \text { бизнес } \\
\text { В2B - business to business }\end{array}$ & $\begin{array}{c}\text { взаимодействие бизнес-структур в электронной коммерции, } \\
\text { предоставление маркетинговых и информационных услуг } \\
\text { через Интернет, электронные платежные расчеты }\end{array}$ \\
\hline $\begin{array}{c}\text { бизнес }- \text { потребитель } \\
\text { В2C - business to consumer }\end{array}$ & $\begin{array}{c}\text { электронная торговля через Интернет-магазины, } \\
\text { предоставление электронных бизнес-услуг потребителям }\end{array}$ \\
\hline $\begin{array}{l}\text { потребитель - потребитель } \\
\text { C2C - consumer to consumer }\end{array}$ & $\begin{array}{l}\text { электронное взаимодействие покупателей между собой: } \\
\text { интернет-аукционы, продажа товаров и услуг через веб- } \\
\text { порталы, участие в форумах, обмен бизнес-информацией }\end{array}$ \\
\hline
\end{tabular}

Источник: составлено автором

Кроме В2В электронных отношений, формируется информационное пространство бизнеса и потребителей с государственными институтами (G2B, $\mathrm{G} 2 \mathrm{C}$ ), которые в свою очередь переформатируют формат своей деятельности в электронный - G2G (табл. 3).
Таблица 3 -
Электронное
взаимодействие
субъектов

предпринимательства и граждан с государственными органами

\begin{tabular}{|c|c|}
\hline Субъекты & Направления электронного взаимодействия \\
\hline $\begin{array}{l}\text { государство - бизнес } \\
\mathrm{G} 2 \mathrm{~B} \text { - government to } \\
\text { business }\end{array}$ & $\begin{array}{c}\text { электронное взаимодействие государственных органов и } \\
\text { представителей бизнеса: электронные транзакции, электронная } \\
\text { регистрация, электронная идентификация; электронные сервисы, } \\
\text { электронная система обращений, электронная отчетность, } \\
\text { государственные закупки }\end{array}$ \\
\hline $\begin{array}{l}\text { государство - } \\
\text { гражданин } \\
\mathrm{G} 2 \mathrm{C}-\text { government to } \\
\text { consumer }\end{array}$ & $\begin{array}{c}\text { электронное взаимодействие государственных органов и граждан: } \\
\text { электронная система обращений граждан; предоставление } \\
\text { государственных услуг и информации гражданам в режиме } \\
\text { онлайн, электронное опрос }\end{array}$ \\
\hline $\begin{array}{l}\text { государство - } \\
\text { государство } \\
\mathrm{G} 2 \mathrm{G}-\text { government to } \\
\text { government }\end{array}$ & $\begin{array}{c}\text { онлайн коммуникации и обмен информацией между } \\
\text { государственными ведомствами и организациями; } \\
\text { международный обмен информацией }\end{array}$ \\
\hline
\end{tabular}

Источник: составлено автором 
Важное значение имеет развитие цифровых технологий в государственном секторе экономики. Цифровое правительство и сервисы по оказанию электронных государственных услуг все чаще рассматриваются как средство уменьшения затрат, которые обеспечивают качество услуг гражданам и бизнесу.

Принятые в нашей стране программы стратегического развития информационного общества предусматривают мероприятия, направленные на создание необходимых условий для развития цифровой экономики, формирования информационного общества [1]. При этом цифровые технологии постоянно совершенствуются и объединяются в глобальные сети, интегрируются в различные сферы жизни общества. и меняют глобальную экономику, что в свою очередь требует научных исследований этой проблематики. Страны, которые инвестируют в новые технологии, масштабно проводят экономические реформы, и как следствие, они получают цифровые дивиденды в виде: ускорение роста национальной экономики, поднятие уровня жизни населения, рост количества рабочих мест, повышение качества взаимодействия между субъектами предпринимательства, гражданами и государством.

\section{Исследование выполнено при финансовой поддержке РФФИ в рамках научного проекта № 19-310-90035/19.}

\section{Список литературы}

1. Стратегия развития информационного общества в Российской Федерации на 2017 - 2030 годы от 09.05.2017 г. № 203 [Электронный ресурс] Режим доступа: http://kremlin.ru/acts/bank/41919 [дата обращения 10.04.2020].

2. Доклад о мировом развитии «Цифровые дивиденды» [Электронный pecypc] - Режим доступа: https:// documents.worldbank.org [дата обращения 10.04.2020]

3. Цифровизация экономики [Электронный ресурс] - Режим доступа: https://bit.samag.ru/uart/more/67 [дата обращения 10.04.2020]

4. ARTICLE 19 - международная правозащитная организация, которая содействует защите свободы слова и свободы информации по всему миру [Электронный pecypc] - Режим доступа: https:// www.article19.org [дата обращения 10.04.2020]. 